\title{
POESIA EM SALA DE AULA: DESCOBERTAS E APRENDIZAGENS*
}

\author{
Marcilene Muniz Monteiro Conceição (SEMED/ROO)
}

Sílvia de Fátima Pileggi Rodrigues (UFR)

\section{Considerações iniciais}

O presente trabalho é um relato de experiência envolvendo alunos do Ensino Fundamental de uma escola da rede pública municipal de Rondonópolis, Mato Grosso, e tem como objetivo dialogar sobre uma atividade realizada com o gênero poesia com uma turma do 3ㅇan ano, compartilhando uma experiência pedagógica positiva. A referida turma possui estudantes em diferentes níveis de alfabetização, sendo composta tanto por crianças alfabetizadas e leitoras, quanto por outras em processo de reconhecimento de letras e palavras.

A escolha de trabalhar com texto poético deu-se tanto pelas qualidades estéticas e características do gênero (como ritmo, jogos sonoros, organização em versos, linguagem que possibilita a mobilização de emoções e criatividade, dentre outras) quanto pelas possibilidades de trabalho didático que ele suscita, uma vez que "[...] esses elementos poéticos [...] devem ser experienciados pelos alunos, vivenciados a partir de vários poemas, através da leitura em voz alta e, posteriormente, da discussão em sala de aula" (RO DRIGUES; SOUZA; BERTOLDO, 2018, p. 173).

Será apresentada, neste trabalho, uma atividade desenvolvida com a finalidade de levar os alunos a experienciar os elementos poéticos do gênero, atividade esta que envolveu a reescrita do poema "A casa e seu dono", de Elias José, a elaboração de aldravia e a construção de uma Aldravipeia intitulada "Escola", já que,

[...] para a formação leitora de alunos dos anos iniciais do Ensino Fundamental, importa despertar o gosto pela leitura de poemas, sua apreciação estética, sem ignorar, obviamente, que conhecimentos básicos acerca do gênero podem possibilitar a melhor compreensão e fruição (RODRIGUES; SOUZA; BERTOLDO, 2018, p. 168).

Para contribuir para a formação leitora dos alunos, como relatam as autoras no fragmento anterior, é preciso iniciar o trabalho com a poesia por 
meio da sensibilização, visto que ela "é um jogo de palavras, associado às sonoridades, que traz encanto ao texto poético e propicia prazer ao pequeno leitor (SOUZA, 2004. p. 65).

Portanto, é principalmente no meio escolar que a criança terá uma aproximação e contato com a poesia, pois "[...] é o professor que conhece a sua turma e sabe que poemas indicar, que tipo de discussão pode estimular e como procurar sensibilizar os leitores [...]" (PINHEIRO, 2018, p. 124). Assim, este terá de criar um clima que seja capaz de possibilitar à criança o contato significativo com o texto poético, ampliando o seu repertório de leitura.

\section{Leitura e poesia}

Os estudos realizados por Hélder Pinheiro (2018) têm mostrado que, dentre os gêneros literários trabalhados em sala de aula ou que são trazidos pelos livros didáticos, o poema é pouco trabalhado (ou mais negligenciado). Ele aponta que há vários fatores que contribuem para isso, embora o fato de que, "[...] depois da massificação da literatura infantil e juvenil, a partir dos anos 1970, tivemos um trabalho efetivo que favorecesse a aproximação entre os leitores escolares e a poesia" (PINHEIRO, 2018, p. 12).

Ainda conforme esse autor, os professores dos anos iniciais não trabalham com esse gênero em sala de aula porque não sabem como fazê-lo, já que o livro didático "[...] se prende mais a questões formais (tipos de verso, rimais), teóricos (conceitos como eu lírico), pouco favorecendo para a aproximação lúdica do texto que estimule a percepção da fantasia, da musicalidade e o diálogo do leitor com o texto" (PINHEIRO, 2018, p. 12). Esse tipo de abordagem é pedagogizante e tal função "[...] empenha-se em ensinar, num sentido positivista, transmitindo conceitos definidos [...]" (SOUZA, 2004, p. 64).

Ao discutir o trabalho da poesia em sala de aula, Pinheiro (2018) aborda duas condições, sendo "a primeira condição indispensável é que o professor seja realmente um leitor com uma experiência significativa de leitura", visto que "sem um mínimo de entusiasmo, dificilmente poderemos sensibilizar nossos alunos para a riqueza semântica da poesia". E "a segunda condição é haver sempre uma pesquisa sobre os interesses de nossos alunos" (PINHEIRO, 2018, p. 22, grifos do autor), para que o docente possa apresentar aos alunos títulos que sejam mais atrativos a eles. 
Souza (2004), apoiada nos estudos de Gebara (1997), apresenta quatro momentos para se trabalhar com a linguagem poética, os quais são assim descritos:

[...] o primeiro momento é o da leitura contemplativa, quando o leitor é sensibilizado pelas impressões e emoções estéticas do texto (fruição-prazer). Em seguida, como segundo momento, sugere que os alunos elaborem uma paráfrase, o que os ajudará a localizar indícios que serão importantes para a análise. Depois, o professor deveria situar o autor e a obra, discutindo os aspectos pragmáticos do texto, explicitadores do movimento social da criação. $O$ terceiro momento indicado por Gebara é o da análise, ou seja, da decomposição final do sentido total e unitário do poema em diversos níveis [...] O quarto momento é definido pela autora por síntese. Nessa atividade, prevê-se que professores e alunos discutam todos os constituintes do poema para chegarem a uma interpretação crítica finalizadora do ato da leitura (SOUZA, 2004, p. 68-69, grifos da autora).

Os passos apresentados por Souza e Pinheiro objetivam a ampliação do repertório de leitura dos alunos, fazendo com que eles tenham novas experiências estéticas e de aprendizado.

Desse modo, para se criar o gosto pela leitura de poesia nas crianças, tem que se começar desde a mais tenra idade, "[...] pois a poesia é, segundo Bamberger (1987), o único gênero capaz de despertar leitores em qualquer fase ou faixa etária de leitura" (SOUZA, 2004, p. 64). Esta foi uma das intencionalidades da atividade que será relatada a seguir.

\section{A poesia em sala de aula - relato de uma atividade}

Como dito anteriormente, o poema é um gênero pouco trabalhado em sala de aula. Portanto, com o objetivo de proporcionar aos alunos um contato com o texto poético, com ritmo e musicalidade, foi proposta a atividade que será aqui relatada.

Os alunos que contribuíram com este estudo estavam no 3 ㅇano do Ensino Fundamental de uma escola da rede municipal da cidade de Rondonópolis, Mato Grosso. As atividades desenvolvidas com eles tiveram como ponto de partida os textos "A casa e seu dono", de Elias José, e "A bailarina", de Cecília Meireles. Também foram utilizados outros autores durante a leitura deleite, oportunizando maior contato com outros escritores e produ- 
ções. Outras atividades foram desencadeadas a partir das leituras, como o estudo do gênero poético aldravia, que possibilitou a escrita de uma aldravipeia - conjunto de 20 aldravias, dedicadas a uma palavra - no caso, "Escola". A atividade transcorreu entre os dias 30 de setembro e 06 de novembro de 2019, durante as aulas de Língua Portuguesa, nas quais foram abordados outros tipos de poemas, a fim de ampliar o repertório dos alunos.

Sendo assim, a atividade com o gênero poemas iniciou-se no dia 30 de setembro, com o poema "A casa e seu dono", de Elias José.

\section{A casa e seu dono}

Essa casa é de caco

Quem mora nela é o macaco.

Essa casa tão bonita

Quem mora nela é a cabrita.

Essa casa é de cimento

Quem mora nela é o jumento.

Essa casa é de telha

Quem mora nela é a abelha.

Essa casa é de lata

Quem mora nela é a barata.

Essa casa é elegante

Quem mora nela é o elefante.

E descobri de repente

Que não falei em casa de gente.

(ELIAS JOSÉ, 2013)

Foi entregue aos alunos uma cópia do poema e, em seguida, foi realizada a leitura silenciosa e, posteriormente, a coletiva, sendo que cada um leu uma estrofe. Estabeleceu-se um diálogo sobre o texto, explorando a compreensão, se a leitura foi agradável, divertida e por quê.

Na sequência, procedeu-se a explicações sobre a estrutura, característica e forma do gênero poético. No caso do poema lido, tratava-se de texto composto por sete dísticos, isto é, estrofes formadas por dois versos. Depois, trabalhou-se os pares de rimas contidas no poema. 
Feitas as leituras e a conversa sobre o texto, propôs-se que eles, retirando as palavras finais (que rimavam), criassem outros pares de rimas, trocando os animais e os objetos para, posteriormente, reescrever o poema. Ao final da produção, cada aluno leu o seu poema e, para ilustrar essa primeira atividade, consta, aqui, um exemplo, na Figura 1, em que, ao lado da imagem, tem-se a transcrição do texto:

Figura 1 - Atividade: Paráfrase do poema "A casa e seu dono"

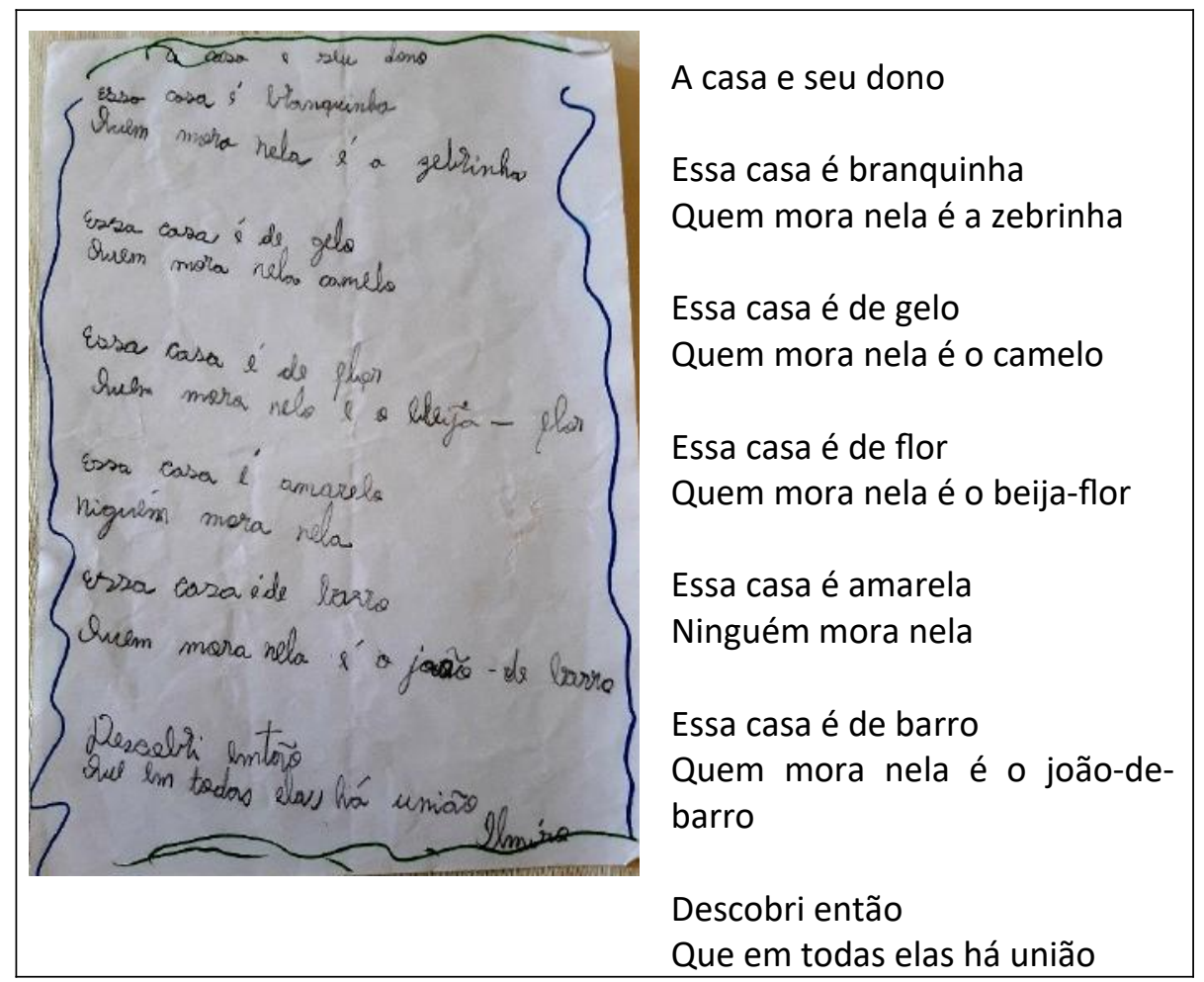

Fonte: Acervo da pesquisadora (2019).

Guardadas as proporções entre o poema de Elias José e o da criança, constata-se que ela conseguiu produzir um texto poético, organizado em dísticos, com rima, coerência e beleza. Fica claro, portanto, que é necessário criar oportunidades de escrita, leitura e fruição estética, pois, se o professor der condições e motivar seus alunos, eles poderão aprender de forma prazerosa e mais significativa. 
No dia 21 de outubro de 2019, foi trabalhado o poema "A bailarina", de Cecília Meireles (1990), com o objetivo de aprofundar o conhecimento sobre estrofe e a musicalidade proporcionada pelas rimas no texto.

\author{
A bailarina \\ Esta menina \\ tão pequenina \\ quer ser bailarina. \\ Não conhece nem dó nem ré \\ mas sabe ficar na ponta do pé. \\ Não conhece nem mi nem fá \\ mas inclina o corpo para cá e para lá. \\ Não conhece nem lá nem si, \\ mas fecha os olhos e sorri. \\ Roda, roda, roda com os bracinhos no ar \\ e não fica tonta nem sai do lugar. \\ Põe no cabelo uma estrela e um véu \\ e diz que caiu do céu. \\ Esta menina \\ tão pequenina \\ quer ser bailarina. \\ Mas depois esquece todas as danças, \\ e também quer dormir como as outras crianças. \\ (MEIRELES, 1990, p. 20)
}


Figura 2 - Atividade: Poema "A cidade florestal"

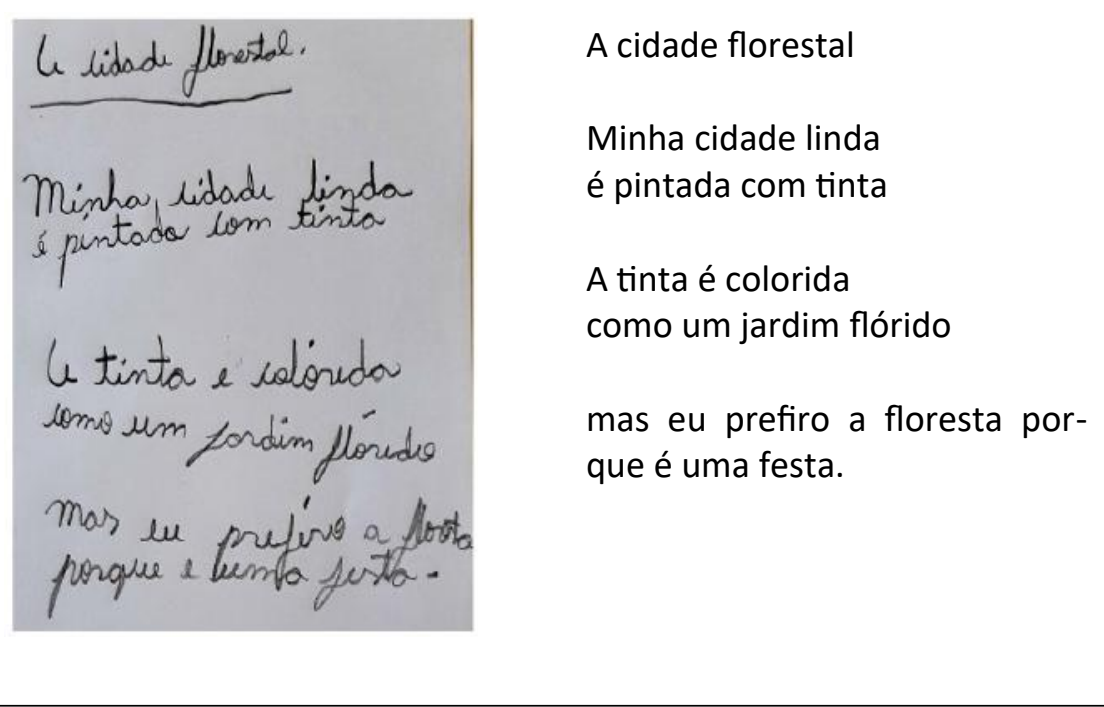

Fonte: Arquivo da pesquisadora (2019).

Já no texto abaixo, a criança fez um jogo interessante com as palavras "cágado" e "cagado". Embora ela soubesse a diferença - tendo em vis ta que jogou com isso -, esqueceu-se de colocar o acento, no momento da escrita. Assim, para o leitor, pode soar estranho e pouco compreensível. Para facilitar a leitura, optou-se, neste caso, por colocar, ao lado da produção da criança, a transcrição com a acentuação adequada.

Figura 3 - Atividade: Poema "O cágado e o banhado"

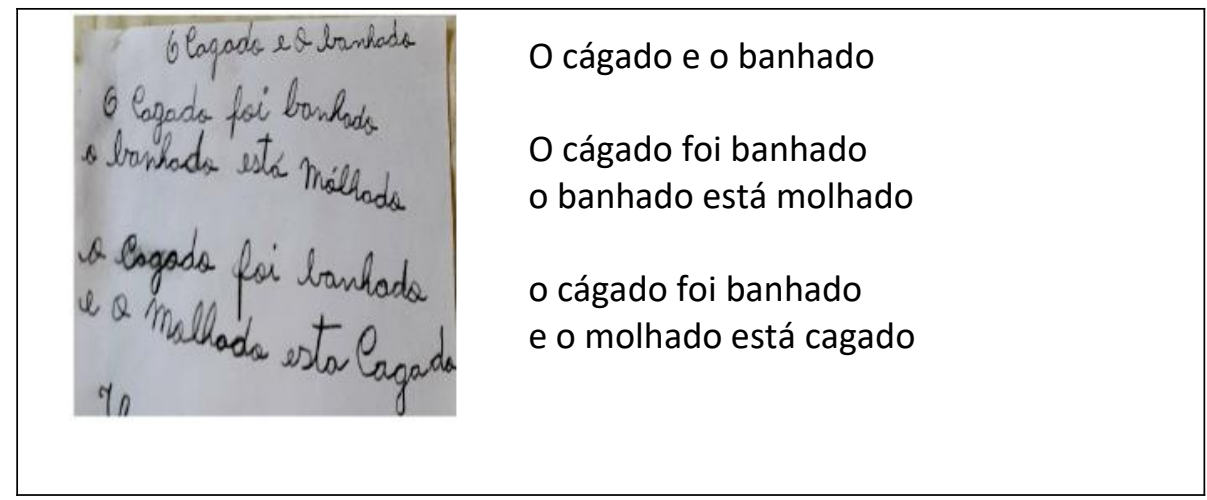

Fonte: Arquivo da pesquisadora (2019). 
Além disso, chama a atenção o uso da palavra "banhado". É importante informar que, no estado de Mato Grosso, é comum usar a expressão banhar-se (tomar banho) e banhado (aquele que tomou banho); banhado também equivale a brejo, charco, área alagadiça. Como é possível observar na leitura atenta do texto, o trocadilho de palavras não tirou a coerência textual e há presença de humor.

Objetivando aprimorar as habilidades de escrita dos alunos, no dia 31 de outubro de 2019 foi trabalhada a reescrita de texto para que, coletivamente, professora e crianças o problematizassem e fizessem a análise linguística. Para tanto, foi escolhido e transcrito, para uma cartolina, o poema de um aluno, que foi, depois, afixado no quadro para que todos pudessem participar e acompanhar. A premissa norteadora dessa atividade foi a de que,

[...] quando explicitadas as condições de produção, a revisão textual contribui para que a criança, desde muito cedo, (re)elabore concepções acerca da estrutura textual considerando aspectos relativos ao nível de informatividade do texto, à ortografia, à caligrafia, à concordância, entre outros. $O$ processo de reflexão acerca desses aspectos está intimamente ligado à compreensão de que se escreve para um interlocutor e que a compreensão do que foi dito demanda que não faltem informações, que a letra esteja legível, que não haja problemas na formalização da escrita que comprometam a construção da interlocução (ROCHA, 2003, p. 73).

Assim, a professora lia um trecho do texto e perguntava se a palavra estava certa ou se estava faltando alguma coisa. Os alunos iam apontando os erros e dando as respostas certas para a correção. Nesse momento, a docente chamou a atenção para os sinais de pontuação, os sinais gráficos que também fazem parte de algumas palavras, como o pingo na letra i, que muitas crianças deixam de colocar ou o fazem como um acento agudo e insistem em dizer que está correto. Também foi apontado como é construída uma estrofe e como se dá a composição das rimas, ressaltando que nem todos os poemas contém rimas.

No dia 04 de novembro de 2019, foi apresentada aos alunos a aldravia, uma nova forma de poesia que

Trata-se de um poema sintético [...] O Poema é constituído numa linométrica de até 06 (seis) palavras-verso. [...] Esse limite de 06 palavras se dá de forma aleatória, porém preocupada com a produção de um poema que condense significação com um mínimo 
de palavras, [...] sem que isso signifique extremo esforço para sua elaboração (DONADON-LEAL, 2010, p. 02)

Por meio de uma aula expositivo-dialogada, foi entregue aos alunos um pequeno texto contendo as informações sobre o gênero para que eles o compreendessem, também foi explicado que o conjunto de 20 aldravias de uma mesma palavra formava uma aldravipeia. Para que eles conhecessem o que era uma aldravipeia, exemplos foram disponibilizados aos alunos e lidos com eles.

Após explorar esse tipo de poesia, foi solicitado que eles escrevessem uma aldravia com a palavra Escola. Concomitantemente, a professora fez a correção ortográfica com os alunos para que, posteriormente, construíssem uma aldravipeia, conforme pode ser visto na Figura 4, a seguir:

Figura 4 - Aldravipeia - Escola

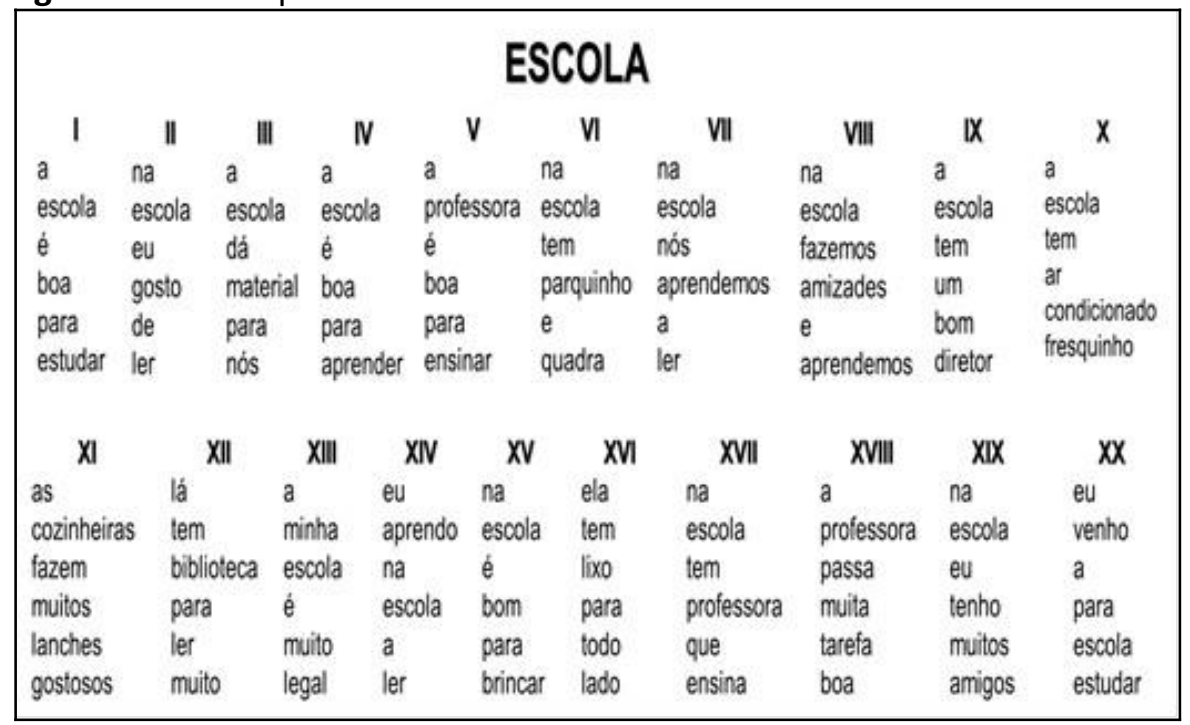

Fonte: Acervo da pesquisadora (2019).

Essa produção escrita foi apresentada para toda a escola durante o momento cívico, ocasião essa em que se congregam os demais alunos e a comunidade escolar. Assim, essa atividade despertou o interesse não só dos participantes, mas também dos outros estudantes que assistiram à apresentação. 


\section{Considerações finais}

Ao fim deste trabalho, e com base na experiência da pesquisadora e em sua vivência no cotidiano escolar, é possível dizer, que muitos professores dão mais valor aos textos em prosa que aos poéticos, mas isso tem mudado aos poucos, já que alguns docentes, ainda que timidamente, têm se esforçado para incluir o gênero poema em seu planejamento. Muito há que se fazer para desmistificar a compreensão por parte desses profissionais para despertar o interesse deles e, consequentemente, de seus alunos.

Aqui foi apresentada parte de um trabalho com o gênero em estudo, que foi realizado com os alunos. Caso o leitor se interesse em conhecer mais profundamente sobre a temática, indicamos as obras de Souza (2004) e Pinheiro (2018), que se constituíram como referências neste texto.

De acordo com Souza (2004, p. 76, grifos da autora), “é possível realizar com os alunos atividades que possam levá-los a descobrir os vários significados da palavra poética, revelando que essas palavras não se gastam, são sempre novas", como pode ser visto no texto "O cágado e o banhado", em que a criança utilizou uma variação de um tipo de quelônio, o cágado, e o termo popular para se referir a quem defecou e está sujo, emporcalhado. Quando foi questionada se sabia o que significava essa palavra, ela disse que era um tipo de tartaruga. Nota-se que ela traz para seu texto os conhecimentos que já possui.

Ao trabalhar em sala de aula com o gênero poético, percebeu-se o interesse dos alunos por lê-lo, pois foram textos curtos, cheios de rimas, melodiosos. Além disso, os participantes se sentiram capazes de, dentro de suas potencialidades, experimentar o lugar de autoria.

Desse modo, diante do que foi exposto neste trabalho, conclui-se que "a poesia, quando bem-ensinada, desencadeia em seus leitores processos emocionais, [...] mostra aos alunos outros espaços até então desconhecidos" (SOUZA, 2004 p. 76). Afinal, como diz o poeta Manoel de Barros, "A poesia está guardada nas palavras - é tudo o que eu sei." (BARROS, 2010, p. 403), e trabalhar com esse gênero dá ao professor a oportunidade de compartilhar esse segredo com as crianças, ao permitir que elas viajem a outros lugares, vejam, sintam, vivam e se emocionem, por meio da musicalidade e do ritmo das palavras. 


\section{Referências}

BAMBERGER, Richard. Como incentivar o hábito da leitura. São Paulo: Ática, 1987.

BARROS, Manoel de. Poema. In: Poesia completa. São Paulo: Leya, 2010, p. 403.

DONADON-LEAL, J. B. Aldravia - nova forma, nova poesia. In. Jornal Aldrava Cultural. no. 88. dezembro de 2010. Disponível em: https://www.jornalaldrava.com.br/pag_aldravias.htm. Acesso em: 26 jan. 2020.

GEBARA, Ana Elvira Luciano. O poema, um texto marginalizado. In. BRANDÃO, H. et al. Aprender e ensinar com textos didáticos e paradidáticos. São Paulo: Cortez, 1997.

JOSÉ, Elias. A casa e seu dono. Blog Poesias e músicas infantis. Publicado em 07 de março de 2013. Disponível em: http://poesiasemusicasinfantis.blogspot.com/2013/03/a-casa-e-o-seu-dono-elias-jose.html. Acesso em: 24 jul. 2020.

MEIRELES, Cecília. A bailarina. In: MEIRELES, Cecília. Ou isto ou aquilo. Ilustrações de Beatriz Berman. 23. imp. Rio de Janeiro: Nova Fronteira, 1990 , p. 20

PINHEIRO, Hélder. Poesia na sala de aula. São Paulo: Parábola, 2018.

ROCHA, Gladys. O papel da revisão na apropriação de habilidades textuais pela criança. In: ROCHA, Gladys; VAL, Maria da Graça Costa (org.). Reflexões sobre práticas escolares de produção de texto - o sujeito-autor. Belo Horizonte: Autêntica, 2003. (p. 69-83)

RODRIGUES, Sílvia de F. Pilegi; SOUZA, Renata J. de; BERTOLDO, Sandra Regina Franciscatto. Estratégia de leitura - reflexões e proposições a partir do livro didático. In. WILLIS, Arlette Ingram et al. Leitura, livros e leitores em diferentes contextos. Rio Grande: EdFURG, 2018, p. 155-184. 
SOUZA, Renata Junqueira de. Leitura e alfabetização: a importância da poesia infantil nesse processo. In. SOUZA, Renata Junqueira de (org.) Caminhos para a formação do leitor. São Paulo: DCL, 2004, p. 62-78. 